
\title{
One-dimensional Transport Simulation of Pollutants in Natural
} Streams

\author{
Mostafa Ramezani', Mahdi Karami², Amin Sarang \\ ${ }^{1}$ Department of Environmental Engineering, Graduate Faculty of \\ Environment, University of Tehran, Tehran, Iran \\ ${ }^{2}$ Department of mathematics, North Branch of Tehran, Azad \\ Islamic University, Iran \\ Study Area: Mackinaw river, U.S., state of Illinois, \\ Chattahoochee river, Georgia, U.S. \\ Coordinates: $40^{\circ} 55^{\prime} 17^{\prime \prime} \mathrm{N}, 89^{\circ} 73^{\prime} 23^{\prime \prime} \mathrm{W} \&$ \\ $33^{\circ} 99^{\prime} 25^{\prime \prime} \mathrm{N}, 84^{\circ} 32^{\prime} 83^{\prime \prime} \mathrm{W}$ \\ Key words: Advection Dispersion Equation, \\ Numerical Modeling, Surface Water Quality.
}

\section{Introduction:}

Fresh and easy to extract the water regarding costs and quality, is always a concern to humankind, even if we are not in explicit drought conditions. From pre-historic era to the present age people have preferred to colonize near freshwater bodies, preferably freshwater lakes and rivers. Since rivers are the most reliable water resources, they also gradually become the most populated zones of the earth (Maisels, 1993).Rivers also play an important role in providing water for every human life uses. Rivervalleys and plains provide fertile soils. Farmers in dry regions irrigate their cropland using water carried by irrigation ditches from nearby rivers. As a river ages, it begins to smooth out the geography of the land around it, making the land on its flood plain flatter which is helpful for building the cities. Therefore these activities such as building cities and consequently establishing industrial areas around rivers are mainly causing rivers to being polluted. Waste water that runs through city sewers or produced by industrial processes, irrigation runoff from agricultural farms, mining effluents, and landfills' drainage degrade water bodies quality. The free surface streams, which flows from upper to downstream either in manmade or in natural streams especially by seasonal rain runoff and/or rivers, can be regarded as one of the most complex physicochemical mechanisms which are highly vulnerable to the above-mentioned contamination resources. Considering the above points,it is the common concept that water quality must meet minimum standards stated by regulatory agencies for each activity. In this

\section{Abstract}

Rivers are the main sources of freshwater systems which governments need to manage and plan to maintain them as per an acceptable quality. In this research, a numerical scheme was used and implemented in MATLAB to provide a one-dimensional water quality tool. This code then was tested with two datasets of Chattahoochee and Mackinaw rivers. To evaluate the model performance, results and sampled data were checked in terms of conformity by using three metrics: CE, MARE, and RMSE. Results were almost near to observed data and metrics' values were found satisfactory, showing that the employed numerical approach is an appropriate method for surface water quality planning and management.

regard, water quality agencies and policy makers are in need of reliable tools which could provide them a good understanding of pollutions' existence in water bodies(Loucks et al., 2005). Advection-Dispersion Equation (Equation-1) is one of the main mathematical models to describe mass transmission in water bodies. There are several solutions available to this important equation such as analytical, numerical and semianalytical solutions.The differences between these solutions for ADE are mainly in their initial mathematical model inputs such as their boundary and initial conditions. Almost all the existing analytical approaches to this equation involve simple boundary conditions. This means that, using simple analytical models restrict model application due to geometry issues (Jaiswal et al., 2011). However, already analytical solutions are available to solve ADE in some certain simplified conditions, in many of real-world water quality problems, achieving to enough accurate result without using numerical approaches is not possible. In this research, modeling of more complex riverine geometries was achieved using a MATLAB code. This code has been developed to estimate water quality conditions in downstream of waste discharge points.

\section{Methods and Materials:}

Advection and diffusion are two fundamental processes by which, mass transportation can being modeled in natural riverine systems. The motion of water is the main cause of advection, moving a polluted portion of streaming water forward. This is always a forward movement while 
dispersion carries dissolved material both forward and backward. By putting such concepts together the transport process for a constituent is described by the ADE (Eq.-1).

$$
\frac{\partial \mathrm{C}}{\partial \mathrm{t}}=\mathrm{D}_{\mathrm{x}} \frac{\partial^{2} \mathrm{C}}{\partial \mathrm{X}^{2}}=\mathrm{U} \frac{\partial \mathrm{C}}{\partial \mathrm{x}}
$$

The $U(\partial C / \partial x)$ term of $A D E$, is mathematical representation of advection process, and $\mathrm{D}_{\mathrm{x}}\left(\partial^{2} \mathrm{C} / \partial \mathrm{x}^{2}\right)$ represents dispersion, which is the cause of widening of initial distribution of dissolved mass back and forth in river.C is concentration (ppm), Dx is longitudinal dispersion coefficient $\left(\mathrm{m}^{2} / \mathrm{sec}\right)$, $U$ is mean stream velocity $(\mathrm{m} / \mathrm{sec})$, $\mathrm{t}$ is time $(\mathrm{sec})$ and $\mathrm{x}$ relates to length.

As is presented in Eq.-1, $D_{x}$ is needed to be determined before model being run. There are plenty available formulas to determine this coefficient however not all of them have appropriate performance (Noori et al., 2009; Noori et al., 2011). Due to some newly published studies in the related literature, authors came to the conclusion to choose $\mathrm{D}_{\mathrm{x}}$ that is suggested by Zeng \& Huai (2014)in this study (Eq.-2). There are many reliable tools to derive a functional dispersion coefficient $\left(D_{x}\right)$ to use in ADE, Such as ANN, ANFIS, SVM, and GC techniques (Noori et al., 2015). However, Zeng \& Huai (2014), provided this expression with a regression analyses on 116 series of available datasets of rivers of US and UK.

$$
\frac{\mathrm{D}_{\mathrm{x}}}{\mathrm{dU}^{*}}=3.563\left(\frac{\mathrm{U}}{\sqrt{\mathrm{gd}}}\right)^{-0.411}\left(\frac{\mathrm{B}}{\mathrm{d}}\right)^{0.6776}\left(\frac{\mathrm{U}}{\mathrm{U}^{*}}\right)^{1.0132}(2)
$$

Where $D_{x}$ is longitudinal dispersion coefficient $\left(\mathrm{m}_{2} / \mathrm{sec}\right), \mathrm{B}$ is average river width $(\mathrm{m}), \mathrm{d}$ is average river depth $(\mathrm{m}), \mathrm{U}$ and $\mathrm{U}^{*}$ mean stream velocity and shear velocity respectively $(\mathrm{m} / \mathrm{sec})$, $g$ is earth gravitational acceleration $\left(\mathrm{m} / \mathrm{sec}_{2}\right)$.

Numerical approach specification: ADE is an appropriate theoretical model to simulate solute transport problems; however, it needs to be represented in a more practical form and implemented in a programming language like MATLAB to be used in real problems.Regarding the natural river streams, which are in most cases their hydraulic properties vary by time passage, we need a time variable solution to Eq.-1. Therefore Chapra (1997) provided Eq.-3 as a solution to ADE. He did this, by writing a mass balance for a onedimensional river system and using a control volume approach. In this approach, the river is assumed to be constituted out of computational cells.If there are any dissolved mass inside river's water, the input and output of the mass which is being transported through one individual cell should be the same, finally by collecting terms, Eq.-3 yields:

$$
\begin{aligned}
& C_{\mathrm{l}+1, \mathrm{i}}=\frac{\mathrm{W}_{\mathrm{li}}}{\mathrm{V}_{\mathrm{i}}} \Delta \mathrm{t}-\frac{\Delta \mathrm{t}}{\mathrm{V}_{\mathrm{i}}}\left(-\mathrm{Q}_{\mathrm{i}} \alpha_{\mathrm{i}}-\mathrm{E}_{\mathrm{i}}\right) \mathrm{C}_{\mathrm{li}-1}+\left[1-\frac{\Delta \mathrm{t}}{\mathrm{V}_{\mathrm{i}}}\left(-\mathrm{Q}_{\mathrm{i}} \beta_{\mathrm{i}}+\mathrm{Q}_{\mathrm{i}} \alpha_{\mathrm{i}}+2 \mathrm{E}_{\mathrm{i}}^{\prime}\right)\right] \mathrm{C}_{\mathrm{l}, \mathrm{i}} \\
& -\frac{\Delta \mathrm{t}}{\mathrm{V}_{\mathrm{i}}}\left(\mathrm{Q}_{\mathrm{i}+1+1} \beta_{\mathrm{i}+1}-\mathrm{E}_{\mathrm{i}+1}\right) C_{\mathrm{i}+1}
\end{aligned}
$$

where land 'i' subscripts relate to counting time and spatial cells, Wis representing discharging pollutant load $(\mathrm{gr} / \mathrm{s}), \mathrm{V}$ is segment volume $\left(\mathrm{m}^{3}\right), \mathrm{Q}$ is the river discharge $\left(\mathrm{m}^{3} / \mathrm{s}\right)$, a and $\mathrm{b}$ are intended to manipulate numerical errors and they range from o to 1 , and $E^{\prime}$ is representation of longitudinal dispersion coeff icient equal to $\left(D_{x} \times A\right) / \Delta x$ where $A$ is river section area $\left(\mathrm{m}^{2}\right)$. Parameters with double subscribe relate to interfaces between cells. Fig.1 depicts a schematic form of underlying concepts of the whole transmission and computational processes in Eq.-3.

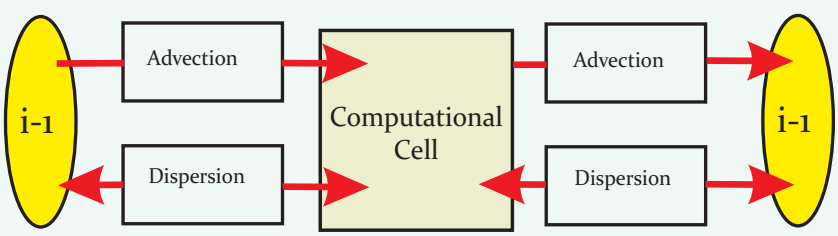

Figure-1: Mass balance around a control volume (Chapra 1997).

From the stability point of view, we have to determine critical time step to limit our model instability likelihood. By VON Neumann analysis it can be shown that the time step should be equal or less than the maximum suggested value by Eq.-4 (Szymkiewicz, 2010).

Model Implementation: in this paper, we have developed a MATLAB code which simulates the transportation of dissolved chemicals in rivers. This part is intended, to assess the performance of introduced scheme (Eq.- 3) in a real engineering problem, therefore two field studies of Mackinaw and Chattahoochee Rivers were modeled. These two datasets were available in Nordin \& Sabol (1974) and Graf (1985) conducted on a branch of Chattahoocheeand Mackinaw River respectively.

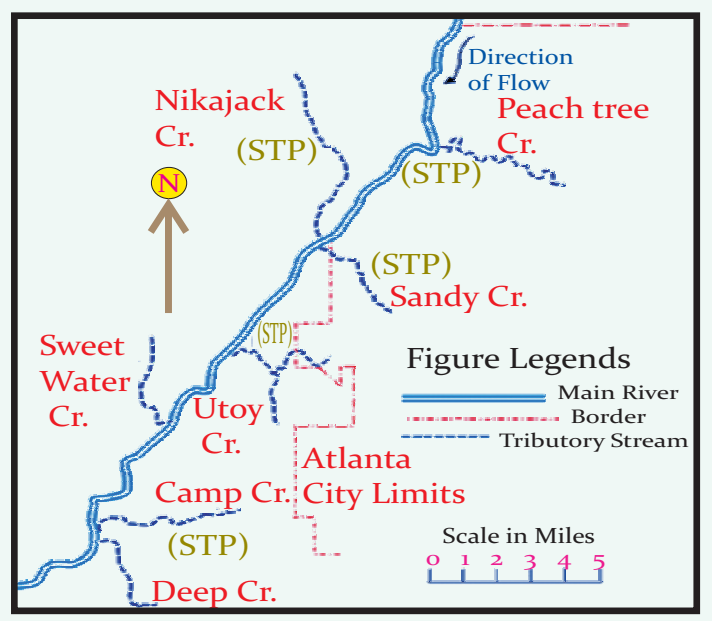

Fiugre-2: Location of injection and sampling site, Chattahoochee River. Borrowed and revised from Nordin \& Sabol (1974) 


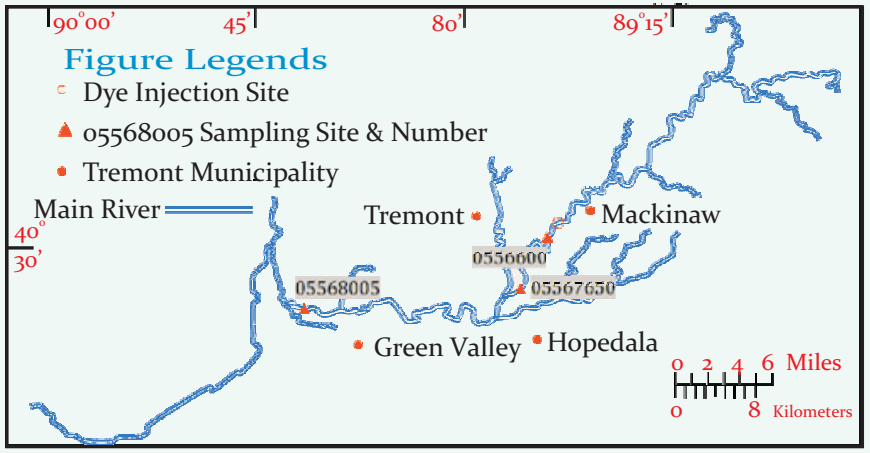

Figure-3: Floodplain Plan of Mackinaw River. Borrowed and Revised From Graf (1985)

The two above-mentioned rivers are shown in Fig. 2 andFig. 3

To form problem domain and main solution matrix (Eq.-5), rivers' length and travel time were divided into small segments regarding spatial and time steps. Mass is assumed to be discharged instantly. The initial solute concentration along the river is assumed to be zero. First and last cells' concentration are assumed to be zero as well (Eq.-6 \& Eq.-7).

Problem Domain: $\left\{\begin{array}{l}\mathrm{n}=\text { Length } / \Delta \mathrm{x} \\ \mathrm{m}=\text { Travel } 1 \text { time } / \Delta \mathrm{t}\end{array}\right.$

Main_Matrix $=\quad\left|\begin{array}{llll}C_{1,1} & C_{1,2} & \cdots & C_{1, n} \\ C_{2,1} & C_{2,2} & \ddots & \vdots \\ \vdots & C_{m, 1} \\ C_{m, 1} & C_{m}, \cdots & C_{1 m, n}\end{array}\right|$

$$
\text { Initial condition }: C(x, 0)=0 \text { for } x \geq 0
$$

$$
\text { Boundary Condition : }\left\{\begin{array}{l}
\mathrm{C}(\mathrm{o}, \mathrm{t})=\mathrm{o} \\
\mathrm{C}(\mathrm{L}, \mathrm{t})=\mathrm{o}
\end{array}\right.
$$

Where $\mathrm{m} \& \mathrm{n}$ relate to counting time and spatial cells, Length or $\mathrm{L}$ is river's length $(\mathrm{m})$, travel time or $\mathrm{t}$ is equal to the length of river divided by mean velocity (sec), $\mathrm{C}$ is solute concentration (ppm). Fig. -4 is a representation of Eq.-5, Eq.-6 \& Eq.-7.

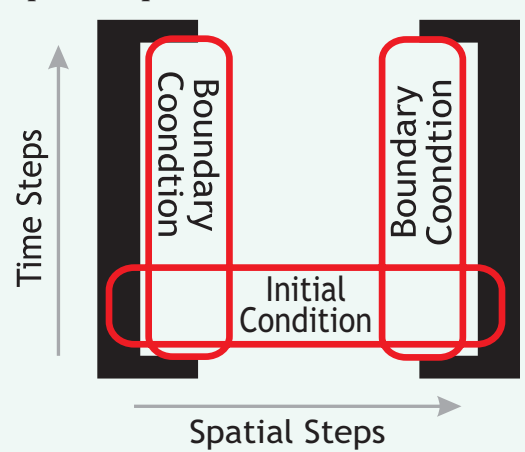

Figure-4: Solution Matrix, initial and boundary condition specif ication of numerical scheme.

\section{Tracerstudyarea:}

Chattahoochee: it is one of most significant natural streams of Southeast of United States of America. Its importance in evaluating of our computational model originates due to the two fundamental factors. First, this river has an intense flow comparing to Mackinaw, and results' goodness suggest that model has a fine performance on higher magnitude events. Moreover, Chattahoochee test case simulation outputs are desirable because of the existences of geometrics and hydraulics differences with Mackinaw River. It seems Chattahoochee has fewer curvatures in its study region and as is common knowledge, the curvature is an effective parameter on mass transmission in rivers. Therefore, simulating such river in terms of mass transportation must be interesting.

Chattahoochee originates from the northeast Georgia highlands and continues southwest about seven hundred kilometers. Arriving Florida, it meets with a branch of Flint River and they form Apalachicola River together. The Chattahoochee watershed consists of about 90 hundred acres. It is the principle source of public water supply for the Atlanta metropolitan areas. At the beginning of the tracer study, an instance loading at the start of the study path of the river was injected to the river. This mass consists of 6218 grams Rhodamine.In the four following downstream stations, solute concentration was measured. Basic gathered information of Chattahoochee presented in Table 1. Mean velocity is about 0.7 meters per hour during the tracer study (Tsivoglou \& Wallace, 1972).

Mackinaw: this river is 209 kilometers long tributary of the Illinois River in the U.S. state of Illinois. Its watershed covers some of the most productive agricultural lands in the United States.Mackinaw River has a wide meandering channel with low banks. The bed is composed of sand and gravel. Graf (1985), considered about $50 \mathrm{~km}$ length of the river to study the pollution transport. Att $=0$, a mass of dye material consisted of 2400 grams was injected to the upstream of the river. After 1.1 and 23.7 hours the peak concentration was detected at 1.9 and 49.9 kilometers downstream the injection point, revealing the mean stream velocity about $0.5(\mathrm{~m} / \mathrm{s})$. Raw geometric and hydraulic data of Mackinaw presented in Table 2.

Model Validation: in this research, a computational piece of written code in MATLAB was used to simulate pollution transportation in one-dimensional water bodies. Further, two tracer studies' datasets (Table 1 \& 2) were employed to assist the performance of the model in real problems. This part of the paper is to assess our model performance, in terms of prediction goodness (RMSE), overall agreement between the observed and modeled datasets (MARE) and coefficient of efficiency (NASH). Therefore a brief description of hydrodynamic metrics and verification is presented here.Eq.-8,is used to 
Table 1: Basic information collected by sampling-measurement stations on Chattahoochee River.

\begin{tabular}{|llllllll|}
\hline $\begin{array}{l}\text { Station Name } \\
\text { \& distance from } \\
\text { injection point }\end{array}$ & $\begin{array}{l}\text { Flow } \\
(\mathrm{m} 3 / \mathrm{s})\end{array}$ & $\begin{array}{l}\text { Time } \\
(\mathrm{Hrs})\end{array}$ & $\begin{array}{l}\text { Drainage } \\
(\mathrm{km} 2)\end{array}$ & $\begin{array}{l}\text { Slope } \\
(1 / 10000)\end{array}$ & Depth $(\mathrm{m})$ & Width $(\mathrm{m})$ & $\begin{array}{l}\text { Observed } \\
\text { Concentration } \\
(\mathrm{ppm})\end{array}$ \\
\hline St1 $=1.500(\mathrm{~km})$ & 140.2 & 2.6 & 4479 & 20 & 2 & 75 & 0.015743071 \\
St2 $=3.100(\mathrm{~km})$ & 141 & 9.6 & 5333 & 25 & 2.3 & 74.1 & 0.007032973 \\
St3 $=65.40(\mathrm{~km})$ & 139.6 & 22.16 & 6291 & 29 & 2.4 & 84.7 & 0.003859966 \\
St4 $=104.6(\mathrm{~km})$ & 139.6 & 38.33 & 6938 & 45 & 2.5 & 100 & 0.002158893 \\
\hline
\end{tabular}

Table 2: Basic information collected by sampling-measurement stations on Mackinaw River.

\begin{tabular}{|c|c|c|c|c|c|c|c|c|}
\hline $\begin{array}{l}\text { Station Name } \\
\text { \& distance from } \\
\text { injection point }\end{array}$ & $\begin{array}{l}\text { Flow } \\
\left(\mathrm{m}_{3} / \mathrm{s}\right)\end{array}$ & $\begin{array}{l}\text { Time } \\
\text { (Hrs) }\end{array}$ & $\begin{array}{l}\text { Drainage } \\
(\mathrm{km} 2)\end{array}$ & $\begin{array}{l}\text { Slope } \\
(1 / 10000)\end{array}$ & Depth (m) & Width (m) & $\begin{array}{l}\text { Observed } \\
\text { Concentration } \\
(\mathrm{ppm})\end{array}$ & $\begin{array}{l}\text { Injected } \\
\text { Mass (gr) }\end{array}$ \\
\hline St $1=1.90(\mathrm{~km})$ & 16.2 & 1.1 & 2213 & 61 & 0.5 & 33.5 & $1.317 \mathrm{e}-1$ & 2400 \\
\hline St $2=49.90(\mathrm{~km})$ & 32.6 & 23.7 & 2827 & 61 & 0.5 & 33.5 & $9.18 \mathrm{e}-3$ & \\
\hline
\end{tabular}

calculate the coefficient of eff iciency, CE which is ranges from zero to one but negative scores are also permitted. A perfect model would gain a score as high as one, the highest positive value that this metric shows as a result. If the calculated CE shows a zero, in fact, it indicates that the model is no better than one parameter or "no knowledge" model. A negative value states that the model is performing very poor even worse than a method without any initial data (Dawson et al., 2007).

$$
C E=1-\frac{\sum_{\mathrm{i}=1}^{\mathrm{n}}\left(\mathrm{Q}_{\mathrm{i}}-\mathrm{Q}_{\mathrm{i}}\right)^{2}}{\sum_{\mathrm{i}=1}^{\mathrm{n}}\left(\mathrm{Q}_{\mathrm{i}}-\overline{\mathrm{Q}}\right)^{2}}
$$

Eq.-9, comprises the mean of the absolute error made relative to the observed record. Zero would be the perfect score for this metric. Its result cannot be negative and has no upper limit. It indicates as a ratio of overall agreement between the observed and modeled datasets(Dawson et al., 2007, Khalil et al., 2001).

$$
\text { MARE }=\frac{1}{n} \times \sum_{i=1}^{n} \frac{\sum_{i=1}^{n}\left(\left|Q_{i}-Q_{i}\right|\right)^{2}}{Q_{i}}
$$

Eq.-10 is used to calculate the root mean squared error (RMSE). This metric records the level of overall agreement between the observed and modeled datasets. It is a nonnegative metric that has no upper bound and for a perfect model, the result would be zero. It comprises a weighted measure of the error in which the largest deviations between the observed and modeled values contribute the most. It is computed on squared differences and assessment is thus biased in favor of peaks and higher magnitude events (Dawson et al., 2007).

$$
\operatorname{RMSE}=\sqrt{\frac{\sum_{\mathrm{i}=1}^{\mathrm{n}}\left(\mathrm{Q}_{\mathrm{i}}-\hat{\mathrm{Q}}_{\mathrm{i}}\right)^{2}}{\mathrm{n}}}
$$

\section{Results \& Discussion:}

In this article, results of implemented model are presented. In Table-3, calculated values of three metrics are shown. These metrics are intended to provide a better understanding of model performance. According to Eq.-8 description, the maximum allowed value for $C E$ is equal to 1. Comparing this metric result for our two case studies, it shows better for Mackinaw. This could be due to the intense flow stream of Chattahoochee. While MARE and RMSE score better results for Chattahoochee (Table 3). Reviewing literature, reveals MARE and CE are more sensitive to the forecasting errors that occur in the low magnitudes. It needs to be considered that the dataset of Mackinaw River tracer study has two observatory stations, while, Chattahoochee has four, and, Chattahoochee has an almost extreme higher flow than what Mackinaw has (140 $\left(\mathrm{m}_{3} / \mathrm{sec}\right)$ for $24.4\left(\mathrm{~m}_{3} / \mathrm{sec}\right)$ respectively). All above facts considered, computational code showed a better performance on Chattahoochee and its forecasted results scored better by these three certain metrics. It can be consequences of more available and detailed data of Chattahoochee River (Fig. 5 and Fig. 6).

Table 3. Model evaluation using metrics.

\begin{tabular}{|lll|}
\hline Metric's Name & Chattahoochee River & Mackinaw River \\
\hline CE & 0.807508 & 0.93484 \\
MARE & 0.000844 & 0.00353 \\
RMSE & 0.002296 & 0.01476 \\
\hline
\end{tabular}

By careful comparing of modeled and sampled results of Chattahoochee River (Fig. 5), two distinct trends are observed. The modeled results, follow a more consistent trend than sampled values. This inconsistency in observed concentration line may be caused by an unknown sink and source activity. In three points, observed concentration is being placed under modeled concentration and in one point the situation is reversed. 


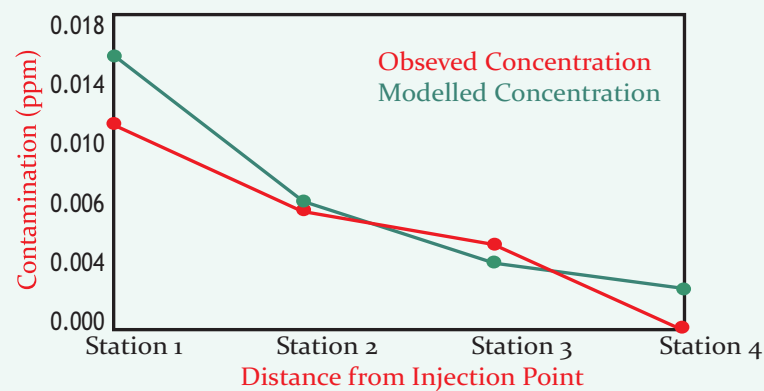

Figure-5: Chattahoochee River, observed and modeled concentration comparison (ppm).

Since Mackinaw River was having only two observatory stations, conducting a comparison of it is modeled and sampled results don't reveal much. However, it can be inferred that after 49 kilometers and even though with the lack of enough observatory stations, the final outcome of the model is in a high conformity with sampled data. Moreover, by comparing proximity of start and end of lines in Fig. 6 it can be concluded, that, the stability restrain (Eq.-4) prevented the model from being unstable.

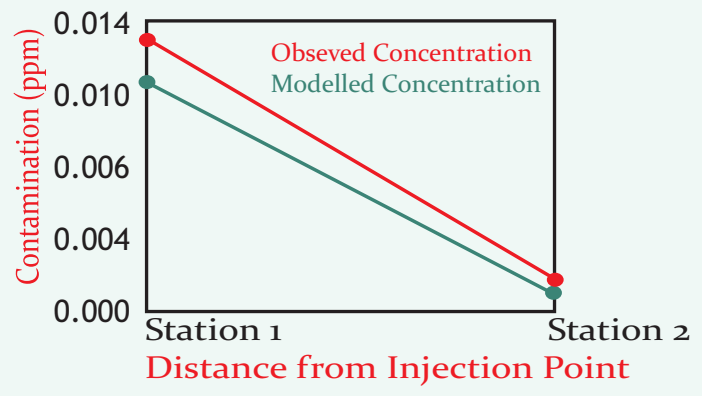

Table 1: The frequency of resistance strains of species (Spp.) 1.-Proteus, 2.-Morganella and 3.-Providencia

\section{Discussion:}

ERivers could be referred as arteries of the earth which need proper care. A systematic management and planning is required for such care and for which we need reliable tools to organize and shape our policies. Water quality modeling using computers is one of most money and time-saving tools that we can employ to achieve this end. This research presents a combined methodology to simulate pollutants transport and concentration in rivers. This methodology combines a simple simulator MATLAB code, with three metrics, to produce and compare results with datasets that were available. The one-dimensional model, of course, is only a rough approximation, and one would expect considerable deviation from the theory which actually occurs; however, this one-dimensional code is an appropriate tool because modelers prefer to avoid complexities of cumbersome 2-D or 3-D modeling software when they face with similar problems which discussed in this paper. Generally, the following main conclusions could be drawn from this study:
- Water quality assessment of numerical scheme showed that this model was capable of accurately simulating pollutant's concentration in a 1-D natural open channel, in a way that the simulated results were close to the observed data.

- This method is able to model more complex spatial and initial distribution of pollution; however, in this study, the initial concentration along the river is assumed to be equal to zero.

- The presented method enables us to build several scenarios of pollutant discharge into one-dimensional water bodies and test each one on many cases, simply by knowing flow and cross sectional dimensions of few sections' of river. This is completely satisfactory in terms of money and time saving, and is reliable as well.

- The robustness of the presented computational model causes it to be applicable to simulate transmission of

- any other dissolved mass in any other river body.

\section{APPENDIXA: Nomenclature-}

\section{Name Description}

1-D Abbreviated form of one-dimensional.

$\Delta \mathrm{t}$ Time step, used in conducted computational code.

$\Delta \mathrm{x} \quad$ Longitudinal spatial step, used in conducted computational code.

A Area of river cross section. B Cross sectional averagewidth.

C Cross sectional average solute concentration.

d Cross sectional averagedepth.

$\mathrm{D}_{\mathrm{x}} \quad$ Longitudinal dispersion coeff icient.

g Earth's gravitational acceleration

$\mathrm{Q}_{\mathrm{i}} \quad$ Modeled data.

$\mathrm{Q}_{\mathrm{i}} \quad$ Average of modeled data.

$\mathrm{Q}_{\mathrm{i}} \quad$ Observed Data.

$\overline{\mathrm{Q}}_{\overline{\mathrm{i}}} \quad$ Average of observed data.

$\mathrm{R} \quad$ Thehydraulic radius.

S Open channel's longitudinal slope. Sometimes considered as energy line.

t Simulated lapsed time.

U Average cross sectional velocity in open channel.

$\mathrm{U}^{*} \quad$ Shearvelocity

\section{Acknowledgements:}

This research was partially supported by Dr. Roohollah Noori and Dr. Mehdi Mazaheri. We also thank our colleagues from Environment Faculty, University of Tehran; who provided insight and expertise that greatly assisted the research, although they may not agree with all of the conclusions of this paper. 


\section{References:}

Chapra, S.C. (1997): Surface Water-Quality Modeling. Waveland Press, United States of America, pp 844.

Dawson, C.W., Abrahart, R.J. \& See, L.M. (2007): HydroTest: A web-based toolbox of evaluation metrics for the standardised assessment of hydrological forecasts. Environ. Modell.Softw., 22:1034-1052.

Graf, J.B. (1985): Traveltime and Longitudinal Dispersion in Illinois Streams, United states of America. U.S. Geological Survey, water-supply Paper, 2269, P. 72.

Jaiswal, D.K., Kumar, A. \& Yadav, R.R. (2011): Analytical solution to the one-dimensional advection-diffusion equation with temporally dependent coefficients. J.Water Resour. Protec. 3(o1):76-84.

Khalil, M., Panu, U. \& Lennox, W. (2001): Groups and neural networks based streamflow data infilling procedures. $J$. Hydrol., 241(3): 153-176.

Loucks, D.P., Beek, E.v., Stedinger, J.R., Dijkman, J.P.M. \& Villars, M.T. (2005): Water resources systems planning and management An Introduction to Methods, Models and Applications, United Nations Educational UNESCO PUBLISHING, Italy.

Maisels, C.K. (1993): The near east: archaeology in the cradle of civilization. Routledge 29 West 35th Street, New York, NY 10001, London and New York.
Noori, R., Karbassi, A., Farokhnia, A. \& Dehghani, M. (2009): Predicting the longitudinal dispersion coefficient using support vector machine and adaptive neuro-fuzzy inference system techniques. Environ. Eng. Sci., 26(10):1503-1510.

Noori, R., Karbassi, A., Mehdizadeh, H., Vesali-Naseh, M. \& Sabahi, M. (2011): A framework development for predicting the longitudinal dispersion coefficient in natural streams using an artificial neural network. Environ. Prog. Sustain. En. 30(3):439-449.

Noori, R., Deng, Z., Kiaghadi, A. \& Kachoosangi, F. (2015): How Reliable Are ANN, ANFIS, and SVM Techniques for Predicting Longitudinal Dispersion Coefficient in Natural Rivers? J. Hydraul. Eng-ASCE, DOI: 10.1061/(ASCE)HY.19437900.0001062, 04015039.

Nordin, C.F. \& Sabol, G.V. (1974): Empirical data on longitudinal dispersion in rivers. Water-Resources Investigations Report 74-20, US Geological Survey, p. 332.

Szymkiewicz, R. (2010): Numerical Modeling in Open Channel Hydraulics, Springer, p.419

Tsivoglou, E.C. \& Wallace, J.R. (1972): Characterization of stream reaeration capacity, p. 326, U.S. Environmental Protection Agency, Off ice of Research and Monitoring., U.S.

Zeng, Y. \& Huai, W. (2014): Estimation of longitudinal dispersion coeff icient in rivers. J. Hydro-environ. Res., 8: 2-6. 